\title{
Inclusão de Cama de Frango em Dietas à Base de Palma Forrageira (Opuntia ficus- indica Mill) para Vacas Mestiças em Lactação. 1. Consumo e Produção ${ }^{1}$
}

\author{
Maria Carla dos Santos Magalhães ${ }^{2}$, Antonia Sherlânea Chaves Véras 3,5 , Marcelo de Andrade \\ Ferreira $^{3,5}$, Francisco Fernando R. de Carvalho ${ }^{3}$, Paulo Roberto Cecon ${ }^{4,5}$, José Nilson de Melo ${ }^{6}$, \\ Wellington Samay de Melo ${ }^{7}$, Jair Teixeira Pereira ${ }^{6}$
}

\begin{abstract}
RESUMO - Este trabalho foi conduzido objetivando-se avaliar o efeito da inclusão de diferentes níveis de cama de frango (aproximadamente 0;10;20 e 30\%) na matéria seca (MS) de dietas contendo palma forrageira, bagaço de cana-de-açúcar in natura, uréia e farelo de algodão, fornecidas na forma de ração completa, sobre o consumo de nutrientes e a produção de leite de vacas mestiças e verificar o tempo necessário para adaptação dos animais às dietas. Foram utilizadas oito vacas $5 / 8$ Holandês-Gir, após pico de lactação, com produção média de $15 \mathrm{~kg}$ de leite/dia e $420 \mathrm{~kg}$ de peso vivo, distribuídas em dois quadrados latinos $(4 \times 4)$ simultâneos, com quatro períodos, quatro animais e quatro níveis de cama de frango na ração. Os consumos de matéria seca, proteína bruta, fibras em detergente neutro e ácido, carboidratos totais e não-fibrosos e matéria orgânica apresentaram comportamento quadrático significativo, enquanto os consumos de matéria mineral e extrato etéreo aumentaram linearmente com a inclusão de cama de frango nas dietas. A produção de leite, com e sem correção para $4 \%$ de gordura, o teor e a produção de gordura e a eficiência alimentar não foram influenciadas pelo incremento de cama de frango nas dietas. O período de adaptação dos animais às dietas pode ser reduzido para sete dias.
\end{abstract}

Palavras-chave: bovinos de leite, farelo de algodão, nitrogênio não-protéico

\section{Broiler Litter in Forage Cactus Based Diets (Opuntia ficus-indica Mill) for Lactating Crossbred Cows. 1. Nutrients Intake and Milk Yield}

\begin{abstract}
This work was carried to evaluate the effect of diferents of broiler litter inclusion (approximately 0, 10, 20 and 30\%, in dry matter base) with $45 \%$ forage cactus associaded to sugar cane bagasse, urea and cotonsead meal, in total diet form, on nutrient intake and milk yield and to evaluate the time necessary to adaptation of the animals to diets. Eigth lactating $5 / 8$ crossbred Holstein/ Gir cows with $420 \mathrm{~kg}$ of LW and production of $15 \mathrm{~kg} /$ day, were assigned to tratament sequences in a replicated $4 \mathrm{X} 4$ latin square with four periods, four animals and four levels of broiler chiken in the ration. The intakes of dry matter, neutral detergent fiber, acid detergent fiber, total carbohydrates, nonfiber carbohydrates, and organic matter, showed significant quadratic answer. However, mineral matter and ether extrat had linear increase. The milk yeld, milk yeld correct for $4 \%$ of fat, fat level, fat yield and alimentar eficiency showed no significant diference. The adaptation period was complete within seven days.
\end{abstract}

Key Words: cottonsead meal, dairy cows, nonprotein nitrogen

\section{Introdução}

Consumo voluntário, segundo Forbes (1995), é definido como a quantidade de alimento ingerida pelo animal, ou grupo de animais, durante um período de tempo (usualmente um dia) no qual tenham livre acesso ao alimento. Porém, o autor destaca que a ingestão voluntária pode ser inferior ao consumo potencial (quantidade de alimento para satisfazer às exigências nutricionais), em função da composição física ou química do alimento e das limitações do meio ambiente ou do próprio animal.

Segundo Mertens (1994), existem três mecanismos de controle do consumo de alimentos: o físico, que se refere à distensão do rúmen-retículo, em função do teor de fibra na ração; o fisiológico, regulado pelo atendimento da demanda energética; e o psicogênico, relacionado à resposta animal a fatores inibidores ou estimuladores

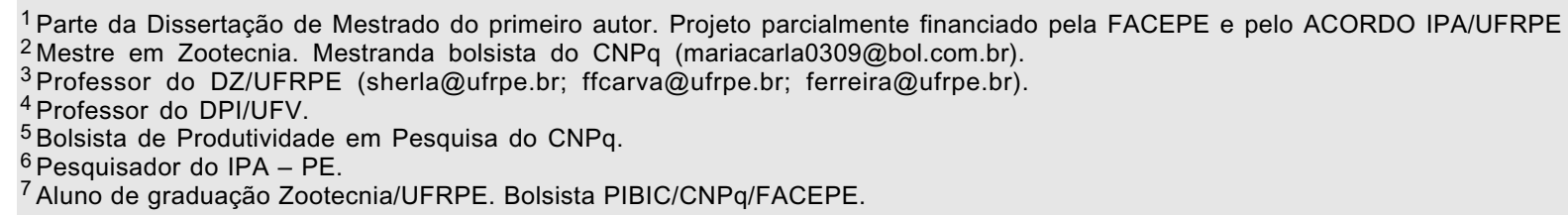


do alimento, do ambiente ou do manejo alimentar.

A fibra pode ser definida como a fração indigestível, ou lentamente digestível, dos alimentos que ocupa espaço no trato gastrintestinal dos animais, limitando, desta forma, a ingestão de alimentos (Mertens, 1997). A fibra em detergente neutro (FDN), por estar relacionada ao efeito de enchimento e à densidade energética do alimento, pode ser utilizada para relacionar os mecanismos de regulação de consumo, em uma mesma escala (Mertens, 1992).

No nordeste brasileiro, a palma (Opuntia ficus indica Mill e Nopalea cochenillifera Salm Dyck) é uma das principais forrageiras utilizadas na alimentação do gado leiteiro, principalmente na estação seca. Todos os cultivares da palma são ricos em carboidratos não-estruturais, mas possuem alto teor de umidade e baixos percentuais de fibra e proteína bruta $(\mathrm{PB})$.

Em razão do baixo teor de matéria seca (MS) da palma forrageira, dietas formuladas com altos percentuais de palma normalmente possuem alto teor de umidade, o que é favorável em regiões onde a água torna-se escassa em determinadas estações. Apesar de o NRC (1989) indicar relação negativa entre consumo de alimentos e conteúdo em umidade das dietas, o NRC (2001), citando Holter \& Urban (1992), relatou que não havia redução do consumo de MS, quando dietas contendo até $30 \%$ de umidade foram fornecidas a vacas em lactação; atribuindo o decréscimo no consumo à fermentação, que geralmente está associada a este tipo de alimento, e não ao conteúdo de água em si.

Santana et al. (1972), utilizando a palma forrageira e a silagem de milho, separadamente e em associação, verificaram que a palma forrageira não deve ser utilizada como volumoso exclusivo na alimentação de vacas de leite.

Ferreira et al. (2000a) avaliaram a associação da palma forrageira com diferentes fontes de fibra (sacharina, silagem de sorgo, bagaço de cana-deaçúcar hidrolizado e bagaço de cana-de-açúcar in natura) na alimentação de vacas mestiças em lactação concluiram que não houve efeito dos diferentes tipos de volumosos sobre consumo de MS, produção de leite e teor de gordura do leite.

O bagaço de cana é um subproduto industrial produzido em larga escala na região nordeste pelas indústrias sucro-alcooleiras, consistindo em boa alternativa para compensar a necessidade de fibra em dietas à base de palma.
De forma semelhante à palma forrageira, a utilização da cama de frango na alimentação de ruminantes tem aumentado consideravelmente durante todo o ano, principalmente quando ocorrem períodos de escassez de forragem. Segundo Conn \& Stumpf (1980), para ruminantes, esse material é uma fonte importante de nitrogênio não-protéico (NNP), na forma de ácido úrico. Porém, a utilização da cama de frango na alimentação de ruminantes deve observar as determinações da Portaria No 290, de 16 de julho de 1997 (Ministério da Agricultura, Pecuária e Abastecimento, 1997).

Segundo Ariele et al. (1991), a cama de frango pode trazer efeitos adversos para a saúde animal mas, quando se emprega até $30 \%$ em dietas para ruminantes, esse problema parece não ocorrer. Além disso, requerem um período de três a quatro semanas para alcançar a máxima ingestão de MS; embora somente cerca de uma semana seja necessária para que os níveis de amônia no rúmen e de uréia no sangue se ajustem.

Considerando os baixos níveis de proteína e de fibra da palma forrageira, a cama de frango representa material de bom valor nutritivo em relação à $\mathrm{PB}$, para uso em associação, constituindo também uma fonte de fibra. Porém, como a cama é, principalmente, fonte de NNP, há necessidade de suplementação com uma fonte de proteína verdadeira como, por exemplo, o farelo de algodão.

Oliveira et al. (2001), avaliando consumo de MS e produção de leite, com 14 dias para adaptação dos animais às dietas experimentais, verificaram, por meio de teste de identidade de modelos, que as equações referentes a estes parâmetros para a segunda e terceira semanas foram semelhantes e concluiram que apenas uma semana seria necessária para adaptação, o que pode significar economia de até $33 \%$ em tempo e alimentos. Da mesma forma, Valadares Filho et al. (2000) também verificaram que a adaptação se completou no período de sete dias.

Conduziu-se este trabalho objetivando avaliar a inclusão de cama de frango (níveis de $0 ; 10 ; 20$ e 30\% na MS) em dietas à base de palma forrageira, constituindo $45 \%$ da MS, além de bagaço de canade-açúcar in natura, uréia e farelo de algodão, para vacas mestiças em lactação, sobre o consumo de alimentos a produção de leite e a conversão alimentar; e verificar a possível redução da duração do período de adaptação de 14 para sete dias, em trabalhos que utilizam dietas à base de palma forrageira e fontes de NNP. 


\section{Material e Métodos}

O experimento foi conduzido na Estação Experimental da Empresa Pernambucana de Pesquisa Agropecuária (IPA), em Caruaru, durante 84 dias, divididos em quatro períodos de 21 dias (14 de adaptação às dietas experimentais e sete para coletas). Antes da implantação do ensaio, os animais permaneceram cerca de 15 dias nas instalações, para adaptação ao manejo.

Foram utilizadas oito vacas 5/8 Holandês Gir, após pico de lactação, com peso vivo médio de $420 \mathrm{~kg}$ e produção de leite média diária de $15 \mathrm{~kg}$, alojadas em baias individuais e distribuídas, aleatoriamente, nos tratamentos que continham, com base na matéria seca (MS), 45\% de palma forrageira (Opuntia ficusindica Mill), cultivar gigante, associados a níveis crescentes de cama de frango $(0 \% ; 10 \% ; 20 \%$ e $30 \%$ ), tendo como substrato a casca de arroz, além de farelo de algodão e bagaço de cana-de-açúcar in natura. Foi adicionada à dieta uréia, visando manter níveis satisfatórios de $\mathrm{PB}$; mistura mineral, para atender aos requerimentos minerais; e monofosfato de amônio (MAP), como fonte de fósforo (Tabelas 1 e 2). As rações foram formuladas de acordo com as recomendações do NRC (1989), para atender às exigências de produção de $15 \mathrm{~kg}$ de leite/vaca/dia, com 4\% de gordura. Na Tabela 3, são apresentadas as composições bromatológicas das misturas e volumosos e, na Tabela 4, das dietas experimentais.
A alimentação foi fornecida na forma de mistura completa, em três refeições diárias, uma pela manhã, às $8 \mathrm{~h}$, e duas à tarde, às $14 \mathrm{e} 17 \mathrm{~h}$, os animais tiveram acesso à água três vezes ao dia.

A produção de leite foi determinada por meio de ordenha diária (pela manhã), com o respectivo registro, somado à diferença entre o peso dos bezerros antes e após a amamentação, que foi permitida à tarde, com duração de, aproximadamente, 20 minutos.

$\mathrm{O}$ manejo dos animais consistiu em coleta e pesagem de sobras (às $6 \mathrm{~h}$ ) e ordenha e liberação dos animais no piquete (às $7 \mathrm{~h}$ ). $\mathrm{O}$ piquete possuía piso de terra, bebedouro e sombreamento natural.

Às $8 \mathrm{~h}$, os animais retornavam às baias, que continham cama de maravalha limpa e alimento fresco disponível nos cochos e permaneciam no local até às $13 \mathrm{~h}$, quando eram novamente soltos no piquete.

Posteriomente, os bezerros eram passados por brete, que continha balança para pesagem, antes e após a mamada. A cuja diferença entre os pesos foi acrescida à produção de leite registrada por ocasião da ordenha, para estimação da produção diária total de leite.

Novamente, às $14 \mathrm{~h}$, as vacas retornavam às baias e recebiam a segunda refeição. Às $17 \mathrm{~h}$, recebiam a última refeição, em quantidade suficiente para que houvesse sobras na manhã seguinte.

O manejo foi realizado durante todo o período experimental, para avaliar a possível redução do tempo de adaptação necessário para estabilizar o

\begin{tabular}{|c|c|c|c|c|}
\hline \multirow[t]{2}{*}{$\begin{array}{l}\text { Ingredientes ( } \% \text { da MS) } \\
\text { Ingredients }(\% \text { of } D M)\end{array}$} & \multicolumn{4}{|c|}{$\begin{array}{l}\text { Níveis de cama de frango ( } \% \mathrm{MS}) \\
\text { Levels of broiler litter (\% of DM) }\end{array}$} \\
\hline & $0 \%$ & $10 \%$ & $20 \%$ & $30 \%$ \\
\hline $\begin{array}{l}\text { Palma } \\
\text { Forage cactus }\end{array}$ & 44,36 & 44,45 & 45,14 & 45,28 \\
\hline $\begin{array}{l}\text { Bagaço de cana-de-açúcar } \\
\text { Sugar cane bagasse }\end{array}$ & 35,86 & 28,93 & 21,39 & 13,40 \\
\hline $\begin{array}{l}\text { Farelo de algodão } \\
\text { Cottonseed meal }\end{array}$ & 17,12 & 14,96 & 12,00 & 9,65 \\
\hline $\begin{array}{l}\text { Cama de frango } \\
\text { Broiler litter }\end{array}$ & 0 & 9,51 & 19,94 & 30,69 \\
\hline $\begin{array}{l}\text { Uréia } \\
\text { Urea }\end{array}$ & 1,38 & 1,13 & 0,83 & 0,37 \\
\hline $\begin{array}{l}\text { Sal mineral } \\
\text { Mineral salt }\end{array}$ & 0,53 & 0,57 & 0,59 & 0,61 \\
\hline $\begin{array}{l}\text { MAP } \\
A P M\end{array}$ & 0,75 & 0,46 & 0,12 & 0,00 \\
\hline
\end{tabular}

R. Bras. Zootec., v.33, n.6, p.1897-1908, 2004 (Supl. 1) 
consumo de matéria seca (MS) e a produção de leite. Para tanto, foi efetuado teste de identidade de modelos, segundo metodologia de Regazzi (1996), utilizandose o programa SAEG (Sistema de Análises Estatísticas e Genéticas) da Universidade Federal de Viçosa (UFV, 1997).

Procedeu-se à análise de identidade de modelos a partir de equações de regressão entre consumo de MS (variável dependente) ou produção de leite (variável dependente), em função dos níveis de inclusão de cama de frango nas dietas (variável independente), obtidas em cada semana de observação; ou seja, na primeira, segunda e terceira semanas. Posteriormente, compararam-se as equações obtidas nas primeira com segunda; primeira com terceira; primeira com segunda e terceira; e segunda com terceira semanas.

Para determinação do teor de gordura do leite, no segundo e quinto dias dos períodos de coleta, os bezerros não mamaram e as vacas foram ordenhadas pela manhã e à tarde, para obtenção de amostras do leite dos dois turnos. Nestes dias, amostras de leite foram coletadas de forma proporcional às produções obtidas nas duas ordenhas e, após homogeneização, foram congeladas para posteriores análises, realizadas com a utilização do método de Gerber, descrito por Behmer (1966). A produção de leite corrigida para $4 \%$ de gordura (PLCG) foi estimada utilizando-se a equação proposta pelo NRC (2001):

PLCG $=0,4 *(\mathrm{~kg}$ de leite produzido $)+15 *(\%$ gordura $)^{*}(\mathrm{~kg}$ de leite produzido $)$

Tabela 2 - Composição percentual das misturas de ingredientes secos

Table 2 - Percentage of the ingredients in the dry mixtures

\begin{tabular}{lcccc}
\hline $\begin{array}{l}\text { Ingredientes (\% MS) } \\
\text { Ingredients (\% DM) }\end{array}$ & \multicolumn{4}{c}{$\begin{array}{c}\text { Misturas } \\
\text { Mixtures }\end{array}$} \\
\cline { 2 - 5 } & $\mathrm{M} 1$ & $\mathrm{M} 2$ & $\mathrm{M} 3$ & $\mathrm{M} 4$ \\
\hline $\begin{array}{l}\text { F. de algodão } \\
\text { Cottonseed meal }\end{array}$ & 86,55 & 56,17 & 35,84 & 23,36 \\
$\begin{array}{l}\text { Cama de frango } \\
\text { Broiler litter }\end{array}$ & 0,00 & 35,73 & 59,55 & 74,28 \\
$\begin{array}{l}\text { Uréia } \\
\text { Urea }\end{array}$ & 6,99 & 4,25 & 2,48 & 0,89 \\
$\begin{array}{l}\text { Sal mineral } \\
\text { Mineral salt }\end{array}$ & 2,69 & 2,13 & 1,76 & 1,47 \\
$\begin{array}{l}\text { MAP } \\
\text { APM }\end{array}$ & 3,77 & 1,72 & 0,37 & 0,00 \\
MAP (many & & & & \\
& & & &
\end{tabular}

MAP (monofosfato de amônio)

APM (amonium phosphate monobasic).

R. Bras. Zootec., v.33, n.6, p.1897-1908, 2004 (Supl. 1)
Para estimativa do consumo, foram efetuadas pesagens e registros diários da quantidade de alimentos fornecidos e das sobras (ajustadas para 10\% do fornecido), objetivando proporcionar o consumo voluntário, porém, garantindo a manutenção das

Tabela 3 - Teores de matéria seca (MS); proteína bruta (PB); extrato etéreo (EE); carboidratos totais (CHOT) e não-fibrosos (CNF); fibras em detergente neutro (FDN) e em detergente ácido (FDA); FDN corrigida para cinza e proteína (FDNcp); matéria mineral (MM); matéria orgânica (MO); proteínas insolúveis em detergente neutro (PIDN) e em detergente ácido (PIDA); nitrogênio não-protéico (NNP) e lignina (LIG) das misturas e dos volumosos das dietas experimentais

Table 3 - Contents of dry matter (DM), crude protein (CP), ether extract (EE), total carbohydrates (TC), nonfiber-carbohydrates (NFC), neutral detergent fiber (NDF), acid detergent fiber (ADF), NDF correct to ash and protein, mineral matter (MM), organic matter (OM), neutral detergent insoluble protein (NDIP), acid detergent insoluble protein (ADIP), non-protein-nitrogen (NPN) and lignin (LIG) of the dry mixtures and forages of experimental diets

\begin{tabular}{|c|c|c|c|c|c|c|}
\hline \multirow[t]{2}{*}{$\begin{array}{l}\text { Nutrientes } \\
\text { Nutrients }\end{array}$} & \multicolumn{4}{|c|}{$\begin{array}{l}\text { Misturas } \\
\text { Mixtures }\end{array}$} & \multicolumn{2}{|c|}{$\begin{array}{l}\text { Volumosos } \\
\text { Forages }\end{array}$} \\
\hline & M1 & M2 & M3 & M4 & $\begin{array}{c}\text { Bagaço }^{2} \\
\text { Bagasse }\end{array}$ & $\begin{array}{l}\text { Palma } \\
\text { Cactus }\end{array}$ \\
\hline $\begin{array}{l}\text { MS (\%) } \\
D M\end{array}$ & 80,19 & 78,99 & 77,23 & 76,80 & 77,95 & 8,72 \\
\hline $\begin{array}{l}\mathrm{PB}^{1} \\
C P\end{array}$ & 46,33 & 38,03 & 32,08 & 28,60 & 2,32 & 5,14 \\
\hline $\begin{array}{l}\mathrm{EE}^{1} \\
E E\end{array}$ & 1,19 & 1,22 & 1,78 & 1,64 & 0,52 & 0,85 \\
\hline $\begin{array}{l}\mathrm{CHOT}^{1} \\
T C\end{array}$ & 44,26 & 48,89 & 50,90 & 52,82 & 92,62 & 86,02 \\
\hline $\begin{array}{l}\mathrm{CNF}^{1} \\
N F C\end{array}$ & 1,87 & 3,66 & 5,55 & 5,24 & 8,23 & 50,93 \\
\hline $\begin{array}{l}\mathrm{FDN}^{1} \\
N D F\end{array}$ & 42,39 & 45,23 & 45,35 & 47,58 & 84,39 & 35,09 \\
\hline $\begin{array}{l}\mathrm{FDA}^{1} \\
A D F\end{array}$ & 28,82 & 28,40 & 26,57 & 27,56 & 65,51 & 23,88 \\
\hline $\begin{array}{l}\text { FDNcp }^{1} \\
\text { NDFap }\end{array}$ & 37,38 & 38,77 & 38,75 & 41,08 & 80,91 & 32,49 \\
\hline $\begin{array}{l}\mathrm{MM}^{1} \\
M M\end{array}$ & 8,23 & 11,87 & 15,24 & 16,95 & 4,54 & 7,99 \\
\hline $\begin{array}{l}\mathrm{MO}^{1} \\
O M\end{array}$ & 91,64 & 88,01 & 85,48 & 84,08 & 95,67 & 92,02 \\
\hline $\begin{array}{l}\mathrm{PIDN}^{1} \\
N D I P\end{array}$ & 1,95 & 3,49 & 4,34 & 4,71 & 1,19 & 1,46 \\
\hline $\begin{array}{l}\mathrm{PIDA}^{1} \\
A D I P\end{array}$ & 1,90 & 1,86 & 1,88 & 1,93 & 1,72 & 1,17 \\
\hline $\begin{array}{l}\mathrm{NNP}^{1} \\
N P N\end{array}$ & 20,70 & 17,19 & 11,94 & 10,88 & 0,73 & 2,45 \\
\hline $\begin{array}{l}\mathrm{LIG}^{1} \\
L I G\end{array}$ & 11,19 & 9,63 & 7,23 & 7,98 & 14,20 & 7,07 \\
\hline
\end{tabular}

$1 \%$ na matéria seca (\% dry matter).

${ }^{2}$ Bagaço de cana-de-açúcar (Sugar cane bagasse). 
proporções dos ingredientes das rações nos diferentes tratamentos experimentais.

As amostras diárias foram caracterizadas por animal, por semana ( $1 \underline{a}$ e $2^{\underline{a}}$ de adaptação e $3 \underline{a}$ de observação), por período e por tratamento e congeladas $\mathrm{a}-15^{\circ} \mathrm{C}$ (com exceção às relativas ao bagaço de cana e aos concentrados). Ao final de cada período, foram homogeneizadas de acordo com a classificação descrita, amostradas, pré-secas e armazenadas. Para análises posteriores, uma alíquota representativa foi retirada e moída em moinho com peneira de malha de $1 \mathrm{~mm}$.

As estimativas dos consumos de MS e de nutrientes foram obtidas determinando-se os teores de MS, matéria orgânica (MO); proteína bruta (PB) e fibra em detergente ácido (FDA), segundo Silva (1990); fibra em detergente neutro (FDN), de acordo com Van Soest (1991); carboidratos totais (CHOT) e consumo de nutrientes digestíveis totais (CNDT), segundo Snifen et al. (1992), obtido em ensaio de digestibilidade conforme Magalhães (2002); e carboidratos nãofibrosos (CNF), segundo Mertens (1997):

$$
\begin{gathered}
\mathrm{CHOT}=100-(\mathrm{PB}+\mathrm{EE}+\text { cinzas }) \\
\mathrm{CNDT}=(\mathrm{PB} \text { ing. }-\mathrm{PB} \text { fecal })+2,25(\mathrm{EE} \text { ing. }- \\
\mathrm{EE} \text { fecal })+(\mathrm{CHOT} \text { ing }-\mathrm{CHOT} \text { fecal }) \\
\mathrm{CNF}=100-(\mathrm{FDN}+\mathrm{PB}+\mathrm{EE}+\text { cinzas })
\end{gathered}
$$

Apenas referentes aos ingredientes da ração, foram feitas análises para os teores de lignina (Silva, 1990); nitrogênio não-protéico (NNP), segundo Licitra et al. (1996); nitrogênio insolúvel em detergente neutro (NIDN) e em detergente ácido (NIDA), e FDN corrigida para cinzas e proteína (FDNcp), relatados por Snifen et al. (1992).

A variação de peso dos animais foi avaliada por medições do perímetro torácico, efetuadas no início e final de cada período experimental, utilizando-se fita graduada, enquanto a eficiência alimentar foi obtida dividindo-se a produção média de leite pela ingestão média de MS verificadas na terceira semana de cada período experimental.

$\mathrm{O}$ delineamento experimental foi em quadrado latino (4 x 4), sendo quatro animais, quatro períodos e quatro níveis de inclusão de cama de frango nas rações. Foram utilizados dois quadrados simultâneos, um com vacas de $4^{\mathrm{a}}$ e outro com vacas de $8^{\mathrm{a}}$ lactação. Os dados foram submetidos às análises de variância e de regressão, utilizando-se o programa SAEG (Sistemas de Análises Estatísticas e Genéticas) da Universidade Federal de Viçosa (UFV, 1997).
Os critérios empregados na escolha do modelo foram a significância dos coeficientes de regressão, observada por meio do teste $\mathrm{F}$, em níveis de 1 e $5 \%$ de probabilidade; o coeficiente de determinação $\left(\mathrm{r}^{2} / \mathrm{R}^{2}\right)$ foi obtido pela relação entre a soma dos quadrados da regressão e a soma de quadrados dos tratamentos e, segundo Sampaio (1998), o fenômeno biológico.

Tabela 4 - Teores de matéria seca (MS), proteína bruta $(\mathrm{PB})$; extrato etéreo (EE), carboidratos totais (CHOT) e não-fibrosos (CNF), fibras em detergente neutro (FDN) e em detergente ácido (FDA), matéria mineral (MM), matéria orgânica (MO), proteínas insolúveis em detergente neutro (PIDN) e detergente ácido (PIDA), nitrogênio-não-protéico (NNP), lignina (LIG) e nutrientes digestíveis totais (NDT) nas dietas experimentais

Table 4 - Contents of dry matter (DM), crude protein (CP), ether extract (EE), total carbohydrates (TC), nonfiber-carbohydrates (NFC), neutral detergent fiber $(N D F)$, acid detergent fiber (ADF), mineral matter (MM), organic matter (OM), neutral detergent insoluble protein (NDIP), acid detergent insoluble

\begin{tabular}{|c|c|c|c|c|}
\hline \multirow[t]{2}{*}{$\begin{array}{l}\text { Nutrientes } \\
\text { Nutrients }\end{array}$} & \multicolumn{4}{|c|}{$\begin{array}{c}\text { Níveis de cama de frango (\% MS) } \\
\text { Levels of broiler litter }(\% D M)\end{array}$} \\
\hline & $0 \%$ & $10 \%$ & $20 \%$ & $30 \%$ \\
\hline $\begin{array}{l}\mathrm{MS}(\%) \\
D M\end{array}$ & 17,22 & 17,20 & 16,97 & 16,91 \\
\hline $\begin{array}{l}\mathrm{PB}^{1} \\
C P\end{array}$ & 12,23 & 13,03 & 13,54 & 14,42 \\
\hline $\begin{array}{l}\mathrm{EE}^{1} \\
E E\end{array}$ & 0,802 & 0,861 & 1,098 & 1,138 \\
\hline $\begin{array}{l}\mathrm{CHOT}^{1} \\
T C\end{array}$ & 80,17 & 78,07 & 75,54 & 73,20 \\
\hline $\begin{array}{l}\mathrm{CNF}^{1} \\
N F C\end{array}$ & 25,87 & 25,96 & 26,44 & 26,34 \\
\hline $\begin{array}{l}\mathrm{FDN}^{1} \\
N D F\end{array}$ & 54,31 & 52,10 & 49,10 & 46,88 \\
\hline $\begin{array}{l}\text { FDA }^{1} \\
A D F\end{array}$ & 39,79 & 37,11 & 33,65 & 30,96 \\
\hline $\begin{array}{l}\mathrm{MM}^{1} \\
M M\end{array}$ & 6,79 & 8,00 & 9,80 & 11,20 \\
\hline $\begin{array}{l}\mathrm{MO}^{1} \\
\mathrm{OM}\end{array}$ & 93,58 & 92,33 & 90,95 & 89,57 \\
\hline $\begin{array}{l}\mathrm{PIDN}^{1} \\
(N D I P)\end{array}$ & 1,46 & 1,92 & 2,37 & 2,77 \\
\hline $\begin{array}{l}\text { PIDA }^{1} \\
A D I P\end{array}$ & 1,51 & 1,51 & 1,53 & 1,55 \\
\hline $\begin{array}{l}\mathrm{NNP}^{1} \\
N P N\end{array}$ & 5,45 & 5,82 & 5,22 & 4,98 \\
\hline $\begin{array}{l}\mathrm{LIG}^{1} \\
L I G\end{array}$ & 10,46 & 9,83 & 8,66 & 8,95 \\
\hline $\begin{array}{l}\operatorname{NDT}(\%)^{*} \\
T D N\end{array}$ & 52,34 & 49,76 & 49,32 & 48,12 \\
\hline
\end{tabular}
protein (ADIP), non-protein-nitrogen (NPN), lignin (LIG) and total digestible nutrients (TDN) on experimental diets

$1 \%$ na matéria seca (\% dry matter).

* Sniffen et al. (1992) 


\section{Resultados e Discussão}

Na Tabela 5, são apresentados os consumos médios de MS, expressos em $\mathrm{kg} / \mathrm{dia}$, percentagem do peso vivo ( $\% \mathrm{PV})$ e em grama por unidade de tamanho metabólico $\left(\mathrm{g} / \mathrm{kg}^{0,75}\right)$; de FDN, em $\mathrm{kg} /$ dia e \%PV; e de FDA, em kg/dia; os respectivos coeficientes de variação e a significância para respostas lineares ou quadráticas.

Constam, na Tabela 6 , os pontos de máxima, os respectivos percentuais de inclusão de cama de frango (CF), os coeficientes de determinação e as equações de regressão.

Os pontos de máxima obtidos para ingestão de MS foram de 17,30 kg/dia; 4,16\%PV; e 187,83 g/ $\mathrm{kg}^{0,75}$, com aproximadamente $14,6 \%$ de inclusão de cama de frango, enquanto, para os consumos de FDN e FDA (em kg/dia), foram de 8,74 e 6,2, para os níveis de $9,92 \%$ e $6,28 \%$ de $\mathrm{CF}$, respectivamente.

Apesar do comportamento quadrático, os consumos de $\mathrm{MS}$, em $\mathrm{kg} / \mathrm{dia}$ e em relação ao peso vivo, foram em média, de 16,44 e 3,94, respectivamente, portanto maiores que os estimados segundo equações do NRC (2001), para vacas leiteiras não-gestantes com $420 \mathrm{~kg}$ de $\mathrm{PV}$, oito semanas de lactação e escore corporal 3,5, produzindo 15 litros de leite/dia com 4\% de gordura, que seriam de, aproximadamente, $13,60 \mathrm{~kg} / \mathrm{dia}$ ou $3,24 \% \mathrm{PV}$ e maiores que o consumo de $3,18 \% \mathrm{PV}$, observado por Ferreira et al. (2000b), em dieta contendo $36 \%$ de palma (em relação à MS) fornecida a vacas holandesas, com produção média de $25 \mathrm{~kg} /$ leite/dia.

Este fato pode estar relacionado à influência de fatores psicogênicos no controle do consumo voluntário, que, provavelmente, foi estimulado pelo fornecimento da alimentação três vezes ao dia. $\mathrm{O}$ manejo adotado proporcionava alimento fresco durante o período diurno, no qual ocorre maior ingestão diária de alimentos (Forbes, 1995).

Por outro lado, considerando que, para animais com as características descritas anteriormente, os consumos de nutrientes digestíveis totais (NDT) e MS, preditos pelo NRC (1989), são de $8,13 \mathrm{~kg} /$ dia e $12,19 \mathrm{~kg} / \mathrm{dia}$, respectivamente, o teor de NDT na dieta seria de $66,73 \%$. Ainda, como o NRC (2001) prediz maior consumo de MS $(13,61 \mathrm{~kg} / \mathrm{dia})$, com ingestão de NDT de $8,15 \mathrm{~kg} / \mathrm{dia}$, a percentagem de NDT na dieta seria de 59,93\%. Portanto, o alto consumo de MS pode dever-se à baixa densidade energética da dieta, cujo teor de NDT foi, em média de, 49,88\% (Tabela 4) e, segundo Mertens (1994), a densidade energética é um dos principais fatores relacionados ao controle do consumo voluntário.

O menor consumo das dietas, a partir de 14,60\% de inclusão de CF (Tabela 6), possivelmente decorreu da redução da palatabilidade da ração, pois, durante

Tabela 5 - Médias e coeficientes de variação (CV) para os consumos de matéria seca (CMS) e des fibra em detergente neutro (CFDN) e em detergente ácido (CFDA), em função dos níveis de cama de frango

Table 5 - Means and coefficients of variation (CV) for intakes of dry matter (DMI), neutral detergent fibre (NDFI) and acid detergent fibre (ADFI), according to the broiler litter levels

\begin{tabular}{|c|c|c|c|c|c|c|c|}
\hline \multirow[t]{2}{*}{$\begin{array}{l}\text { Variáveis } \\
\text { Variables }\end{array}$} & \multicolumn{4}{|c|}{$\begin{array}{c}\text { Níveis de cama de frango } \\
\text { Levels of broiler litter }\end{array}$} & \multirow{2}{*}{$\begin{array}{l}\mathrm{CV} \\
C V \\
(\%)\end{array}$} & \multicolumn{2}{|c|}{$\mathrm{P}$} \\
\hline & $0 \%$ & $10 \%$ & $20 \%$ & $30 \%$ & & $\mathrm{~L}$ & Q \\
\hline $\begin{array}{l}\mathrm{CMS}(\mathrm{kg} / \mathrm{dia}) \\
D M I(\mathrm{~kg} / \text { day })\end{array}$ & 15,68 & 17,56 & 16,71 & 15,84 & 7,69 & NS & 0,010 \\
\hline $\begin{array}{l}\mathrm{CMS}(\% \mathrm{PV}) \\
D M I(\% L W)\end{array}$ & 3,76 & 4,21 & 4,03 & 3,78 & 6,49 & NS & 0,001 \\
\hline $\begin{array}{l}\text { CMS }\left(\mathrm{g} / \mathrm{kg}^{0,75}\right) \\
D M I\left(\mathrm{~g} / \mathrm{kg}^{75}\right)\end{array}$ & 169,89 & 190,15 & 181,61 & 170,89 & 6,76 & NS & 0,002 \\
\hline $\begin{array}{l}\text { CFDN (kg/dia) } \\
N D F I(k g / d a y)\end{array}$ & 8,29 & 9,04 & 8,08 & 7,40 & 8,09 & 0,005 & 0,010 \\
\hline $\begin{array}{l}\text { CFDN }(\% \mathrm{PV}) \\
N D F I(\% L W)\end{array}$ & 1,99 & 2,17 & 1,95 & 1,77 & 7,13 & 0,002 & 0,003 \\
\hline $\begin{array}{l}\text { CFDA (kg/dia) } \\
A D F I(k g / d a y)\end{array}$ & 6,02 & 6,39 & 5,50 & 4,85 & 8,18 & 0,000 & 0,010 \\
\hline
\end{tabular}

R. Bras. Zootec., v.33, n.6, p.1897-1908, 2004 (Supl. 1) 
a condução do experimento, observou-se que a palma forrageira adicionada às misturas com maior percentual de $\mathrm{CF}$, depois de algum tempo, promovia o umedecimento da cama, provocando um cheiro característico.

Observou-se também que as dietas com 10 e $20 \%$ de CF apresentaram maior homogeneidade após a mistura dos componentes e suscitaram maior interesse dos animais. Por outro lado, a grande quantidade de bagaço de cana da dieta com $0 \%$ de $\mathrm{CF}$, não permitia boa homogeneidade e os animais eram capazes de selecionar, em maior intensidade, os componentes de sua preferência.

No entanto, em todos os níveis de $\mathrm{CF}$, houve ingestão de FDN acima da capacidade diária de consumo de FDN (CCFDN), que, segundo Mertens (1992), pode ser calculada utilizando a fórmula: $\mathrm{CCFDN}=1,2 * \mathrm{PV} / 100$, o que representaria, neste trabalho, 5,04 kg de FDN/dia.

Entretanto, Detman et al. (2001), trabalhando com novilhos em crescimento; Moreira et al. (2001), com vacas mestiças Holandês-Zebu; Pereira et al. (2002) e Leite (2002), com vacas holandesas em lactação, encontraram ingestão de FDN de 1,67; 1,59; 1,58 e 1,86\% PV, respectivamente. Allen (1997) relata que pode haver ampliação da capacidade de enchimento, em função de maior consumo, o que torna o entrave físico numericamente relativo e não absoluto, em função da exigência energética.

Apesar de o maior consumo de FDN ter ocorrido com $9,92 \%$ de CF, a maior ingestão de FDA foi atingida com $6,28 \%$ de inclusão de $\mathrm{CF}$, e a maior proporção de FDN proveniente do bagaço de cana, com $0 \%$ de CF (Tabela 7). Desse modo, pode-se inferir, a este nível de inclusão de $\mathrm{CF}$, um menor consumo motivado pelo maior efeito repleção ruminal.

$\mathrm{Na}$ Tabela 8, são apresentados os consumos de $\mathrm{PB}$, de extrato etéreo (EE), de carboidratos totais (CHOT) e não-fibrosos (CNF); de matéria orgânica (MO), de matéria mineral (MM) e de NDT e, na Tabela 9, as respectivas equações de regressão, pontos de máxima, os percentuais de $\mathrm{CF}$ e os coeficientes de determinação.

Os consumos de PB, CHOT, CNF, MO e NDT apresentaram comportamento quadrático, com pontos de máxima em 2,$31 ; 13,39 ; 4,67 ; 15,93$ e $8,60 \mathrm{~kg}$ com 19,$78 ; 11,38 ; 14,54 ; 13,18$ e $11,10 \%$ de $\mathrm{CF}$, respectivamente.

Apesar de as dietas apresentarem, em média, $13,31 \%$ de $\mathrm{PB}$, teor inferior aos $14,52 \%$ recomendados pelo NRC (2001), em todas as dietas experimentais, com exceção da primeira, foi superada a exigência de $1,98 \mathrm{~kg} /$ dia de PB, de acordo com o NRC (2001).

Com exceção da dieta com $30 \%$ de CF, houve

Tabela 6 - Equações de regressão, pontos de máxima $(P M)$ e respectivos níveis de cama de frango (CF); e coeficientes de determinação $\left(R^{2} / r^{2}\right)$ para os consumos de matéria seca (CMS) e fibras em detergente neutro (CFDN) e em detergente ácido (CFDA), em função dos níveis de CF

Table 6 - Regression equations, points of maximum (PM) and respectives levels of broiler litter (BL); and coefficients of determination $\left(R^{2} / r^{2}\right)$ for intakes of dry matter and fibers insolubles in neutral and acid detergent, according to BL levels

\begin{tabular}{|c|c|c|c|c|}
\hline $\begin{array}{l}\text { Variáveis } \\
\text { Variables }\end{array}$ & $\begin{array}{l}\text { Equações } \\
\text { Equations }\end{array}$ & $\begin{array}{l}\mathrm{PM} \\
P M\end{array}$ & $\begin{array}{l}\text { CF } \\
B L\end{array}$ & $\begin{array}{l}\mathrm{R}^{2} \\
(\%)\end{array}$ \\
\hline CMS (kg/dia) & $=15,8114+0,2025290^{\mathrm{NS}} \mathrm{CF}-0,00686804 * * \mathrm{CF}^{2}$ & 17,30 & 14,74 & 84 \\
\hline $\begin{array}{l}D M I \text { (kg/day) } \\
\text { CMS (\%PV) }\end{array}$ & $=3,79214+0,0508292^{\mathrm{NS}} \mathrm{CF}-0,00173993 * * \mathrm{CF}^{2}$ & 4,16 & 14,61 & 88 \\
\hline $\begin{array}{l}\text { DMI }(\% L W) \\
\text { CMS }\left(\mathrm{g} / \mathrm{kg}^{0,75}\right) \\
\text { DMI }\left(\mathrm{g} / \mathrm{kg}^{.75}\right)\end{array}$ & $=171,222+2,26845^{\mathrm{NS}} \mathrm{CF}-0,0774614 * * \mathrm{CF}^{2}$ & 187,83 & 14,64 & 87 \\
\hline $\begin{array}{l}\text { CFDN(kg/dia) } \\
N D F I \text { (kg/day) }\end{array}$ & $=8,38923+0,0708933 * * \mathrm{CF}-0,0035726 * \mathrm{CF}^{2}$ & 8,74 & 9,92 & 85 \\
\hline $\begin{array}{l}\text { CFDN }(\% \mathrm{PV}) \\
N D F I(\% L W)\end{array}$ & $=2,01253+0,017992^{\mathrm{NS}} \mathrm{CF}-0,00089745^{*} \mathrm{CF}^{2}$ & 2,10 & 10,02 & 88 \\
\hline $\begin{array}{l}\text { CFDA }(\mathrm{kg} / \mathrm{dia}) \\
A D F I(\mathrm{~kg} / \text { day })\end{array}$ & $=6,09641+0,031717 \mathrm{CF}^{* *}-0,00252341 \mathrm{CF}^{2 * *}$ & 6,20 & 6,28 & 92 \\
\hline
\end{tabular}

** Significativos a $1 \%$ (significant at $1 \%$ of probability).

* Significativos a $5 \%$ (significant at $5 \%$ of probability).

NS Não-significativo (not significant).

R. Bras. Zootec., v.33, n.6, p.1897-1908, 2004 (Supl. 1) 
ingestão de NDT de acordo com os valores recomendados pelos NRC $(1989,2001)$, confirmando que o aumento do consumo de MS sofreu estímulo da deficiência energética da dieta.

A produção de leite $(\mathrm{PL})$, produção de leite corrigida (PLC), o teor de gordura (TG), a produção de gordura $(\mathrm{PG})$ e a eficiência alimentar (EA) são

Tabela 7 - Contribuição percentual de cada fonte de fibra em detergente neutro (FDN) para o total de FDN das dietas experimentais

Table 7 - Percentage of contribution of each source of neutral detergent fiber (NDF) for total NDF of experimental diets

\begin{tabular}{|c|c|c|c|c|}
\hline \multirow[t]{2}{*}{$\begin{array}{l}\text { Fontes de FDN } \\
\text { Sources of NDF }\end{array}$} & \multicolumn{4}{|c|}{$\begin{array}{l}\text { Níveis de cama de frango } \\
\text { Levels of broiler litter }\end{array}$} \\
\hline & $0 \%$ & $10 \%$ & $20 \%$ & $30 \%$ \\
\hline $\begin{array}{l}\text { Bagaço de cana-de-açúcar } \\
\text { Sugar cane bagasse }\end{array}$ & 55,72 & 46,84 & 36,75 & 24,12 \\
\hline $\begin{array}{l}\text { Palma } \\
\text { Forage cactus }\end{array}$ & 28,66 & 29,94 & 32,26 & 33,89 \\
\hline $\begin{array}{l}\text { Misturas secas } \\
\text { Dry mixtures }\end{array}$ & 15,44 & 23,12 & 30,92 & 41,94 \\
\hline
\end{tabular}

apresentadas na Tabela 10. Observou-se que estas variáveis não foram alteradas significativamente pela inclusão de CF na dieta.

Contudo, apesar de ter havido consumos de PB e de NDT suficientes para produzir 15 litros/dia, a produção média foi de 12 litros/dia. Os teores de nitrogênio não-protéico (NNP) das dietas, em média $5,37 \%$ da MS, podem ter ocasionado aumento na excreção de nitrogênio pela urina, o que demanda energia e pode prejudicar a produção. Oliveira et al. (2001) e Mello et al. (2003) verificaram queda na produção de leite, à medida que incluíram NNP, em níveis de 2,22 até $8 \%$ da MS. Pereira et al. (2001), utilizando dietas contendo uréia e CF com, aproximadamente, $2,3 \%$ de NNP na MS, verificaram $49 \mathrm{~g} /$ dia de excreção urinária diária de nitrogênio em dietas com uréia em sua composição, valor superior ao observado em dietas com CF $(37,14 \mathrm{~g} / \mathrm{dia})$.

Não ocorreu variação do peso vivo dos animais submetidos aos diferentes níveis de CF, que mantiveram bom escore corporal durante todo o experimento. Esse comportamento foi similar ao relatado por Ferreira et al. (2000) e diferente do

Tabela 8 - Médias e coeficientes de variação (CV) para os consumos de proteína bruta (CPB), de extrato etéreo ( $\mathrm{CEE}$ ), de carboidratos totais (CCHOT) e nãofibrosos (CCNF), de matéria orgânica $(\mathrm{CMO})$ e de matéria mineral (CMM) e médias dos consumos de nutrientes digestíveis totais (CNDT) em função dos níveis de cama de frango

Table 8 - Means and coefficients of variation (CV) for intakes of crude protein (CPI), ether extract (EEI), total carbohydrates (TCI), non-fiber-carbohydrates (NFCI), organic matter (OMI), mineral matter (MMI), and means of total digestible nutrients intakes (TDNI), according to the broiler litter levels

\begin{tabular}{|c|c|c|c|c|c|c|c|}
\hline \multirow[t]{2}{*}{$\begin{array}{l}\text { Variáveis } 1 \\
\text { Variables }^{1}\end{array}$} & \multicolumn{4}{|c|}{$\begin{array}{l}\text { Níveis de cama de frango } \\
\text { Levels of broiler litter }\end{array}$} & \multirow{2}{*}{$\begin{array}{l}\mathrm{CV} \\
C V \\
(\%)\end{array}$} & \multicolumn{2}{|c|}{$\mathrm{P}$} \\
\hline & $0 \%$ & $10 \%$ & $20 \%$ & $30 \%$ & & $\mathrm{~L}$ & $\mathrm{Q}$ \\
\hline $\begin{array}{l}\text { CPB } \\
C P I\end{array}$ & 1,91 & 2,29 & 2,24 & 2,23 & 8,55 & 0,011 & 0,014 \\
\hline CEE & 0,12 & 0,14 & 0,18 & 0,17 & 10,98 & 0,000 & 0,014 \\
\hline $\begin{array}{l}\text { CCHOT } \\
T C I\end{array}$ & 12,60 & 13,72 & 12,66 & 11,69 & 7,09 & 0,021 & 0,006 \\
\hline $\begin{array}{l}\mathrm{CCNF} \\
N F C I\end{array}$ & 4,31 & 4,68 & 4,58 & 4,29 & 5,67 & NS & 0,002 \\
\hline $\begin{array}{l}\mathrm{CMO} \\
O M I\end{array}$ & 14,69 & 16,23 & 15,26 & 14,24 & 7,30 & NS & 0,007 \\
\hline $\begin{array}{l}\text { CMM } \\
M M I\end{array}$ & 1,05 & 1,40 & 1,63 & 1,74 & 11,79 & 0,000 & 0,072 \\
\hline $\begin{array}{l}\text { CNDT } \\
T D N I\end{array}$ & 8,21 & 8,74 & 8,23 & 7,61 & 7,37 & 0,036 & 0,020 \\
\hline
\end{tabular}

${ }^{1} \mathrm{~kg} / \mathrm{dia}$ (kg/day)

P. Probabilidade, L. linear, Q. quadrático, NS. não-significativo

P. Probability, L. linear, Q. quadratic, NS. not significant. 
descrito por Santana et al. (1972), que verificaram perda de peso nos animais. Estas observações confirmam a necessidade de incorporação de fontes de fibra em dietas que contêm palma forrageira, visando evitar distúrbios, como diarréias, por exemplo.
Para realizar análise dos custos com alimentação utilizou-se, para palma forrageira, o custo de um centavo de real por quilograma de matéria natural (MN), segundo Santos et al. (1997) e, para os demais ingredientes, os preços de mercado à época do experimento, que foram

Tabela 9 - Pontos de máxima (PM) e respectivas porcentagens de cama de frango $(C F)$, coeficientes de determinação $\left(R^{2} / r^{2}\right)$ e equações de regressão para os consumos de proteína bruta (CPB), de extrato etéreo (CEE), de carboidratos totais (CCHOT) e não-fibrosos (CCNF), de matéria orgânica (CMO) e de matéria mineral (CMM), em função dos níveis de cama de frango

Table 9 - Points of maximum (PM) and respectives levels of broiler litter (BL), coefficients of determination $\left(R^{2} / r^{2}\right)$ and regression equations for intakes of of crude protein $(C P I)$, ether extract (EEI), total carbohydrates (TCI), non-fiber-carbohydrates (NFCI), organic matter (OMI), mineral matter (MMI), and total digestible nutrients intakes (TDNI), according to broiler litter levels

\begin{tabular}{|c|c|c|c|c|}
\hline $\begin{array}{l}\text { Variáveis (kg/dia) } \\
\text { Variables }(\mathrm{kg} / \text { day) }\end{array}$ & $\begin{array}{l}\text { Equações } \\
\text { Equations }\end{array}$ & $\begin{array}{l}\mathrm{PM} \\
P M\end{array}$ & $\begin{array}{c}\mathrm{CF}(\%) \\
B L\end{array}$ & $\begin{array}{l}\mathrm{r}^{2} / \mathrm{R}^{2} \\
(\%)\end{array}$ \\
\hline $\mathrm{CPB}$ & $=1,93445+0,0379275 * \mathrm{CF}-0,000958528 * \mathrm{CF}^{2}$ & 2,31 & 19,78 & 87 \\
\hline$C P I$ & & & & \\
\hline $\mathrm{CEE}$ & $=0,121485+0,00213193 * * \mathrm{CF}$ & - & - & 87 \\
\hline EEI & & & & \\
\hline $\begin{array}{l}\text { CCHOT } \\
T C I\end{array}$ & $=12,7122+0,11884 * \mathrm{CF}-0,00522096 * 6^{*} \mathrm{CF}^{2}$ & 13,39 & 11,38 & 87 \\
\hline $\begin{array}{l}\mathrm{CCNF} \\
N F C I\end{array}$ & $=4,32306-0,047992^{\mathrm{NS}} \mathrm{CF}-0,00165009 * * \mathrm{CF}^{2}$ & 4,67 & 14,54 & 97 \\
\hline $\begin{array}{l}\mathrm{CMO} \\
O M I\end{array}$ & $=14,817+0,168567^{\mathrm{NS}} \mathrm{CF}-0,00639427 * * \mathrm{CF}^{2}$ & 15,93 & 13,18 & 86 \\
\hline $\begin{array}{l}\text { CMM } \\
M M I\end{array}$ & $=1,11223+0,0229663 * * \mathrm{CF}$ & - & - & 95 \\
\hline $\begin{array}{l}\text { CNDT } \\
T D N I\end{array}$ & $=8,25004+0,0637526 * \mathrm{CF}-0,00287209 * \mathrm{CF}^{2}$ & 8,60 & 11,10 & 93 \\
\hline
\end{tabular}

** Significativos a $1 \%$ (significant at $1 \%$ of probability).

* Significativos a $5 \%$ (significant at $5 \%$ of probability).

NS Não-significativo (not significant).

Tabela 10 -Médias, coeficientes de variação (CV) e equações para as variáveis produção de leite $(\mathrm{PL})$, produção de leite corrigida (PLC), teor de gordura $(T G)$, produção de gordura (PG) e eficiência alimentar (EA), em função dos níveis de cama de frango

Table 10 - Means, coefficients of variation (CV) and equations for milk yeld (MY), corrected milk yeld (CMY), milk fat (MF), fat yeld and feed: milk yeld ratio (feed:MYratio), according broiler litter levels

\begin{tabular}{|c|c|c|c|c|c|c|}
\hline \multirow[t]{2}{*}{$\begin{array}{l}\text { Variáveis } \\
\text { Variables }\end{array}$} & \multicolumn{4}{|c|}{$\begin{array}{l}\text { Níveis de cama de frango } \\
\text { Levels of broiler litter }\end{array}$} & \multirow[t]{2}{*}{$\begin{array}{l}\mathrm{CV} \\
(\%)\end{array}$} & \multirow[t]{2}{*}{$\begin{array}{l}\text { Equações } \\
\text { Equations }\end{array}$} \\
\hline & $0 \%$ & $10 \%$ & $20 \%$ & $30 \%$ & & \\
\hline $\begin{array}{l}\operatorname{PL}(\mathrm{kg} / \mathrm{dia}) \\
M Y(k g / \text { day })\end{array}$ & 11,71 & 12,57 & 12,22 & 12,18 & 6,38 & $\hat{\mathrm{Y}}=12,17$ \\
\hline $\begin{array}{l}\text { PLCG }(\mathrm{kg} / \text { dia }) \\
M Y C(\mathrm{~kg} / \text { day })\end{array}$ & 10,99 & 12,28 & 11,65 & 11,36 & 12,27 & $\hat{\mathrm{Y}}=11,57$ \\
\hline $\begin{array}{l}\mathrm{TG}(\%) \\
M F(\%)\end{array}$ & 3,58 & 3,84 & 3,69 & 3,48 & 14,75 & $\hat{\mathrm{Y}}=3,65$ \\
\hline $\begin{array}{l}\mathrm{PG}(\mathrm{kg} / \mathrm{dia}) \\
F Y(\mathrm{~kg} / \text { day })\end{array}$ & 0,40 & 0,46 & 0,42 & 0,419 & 26,44 & $\hat{\mathrm{Y}}=0,41$ \\
\hline $\begin{array}{l}\text { EA }(1 / \mathrm{kg}) \\
\text { Feed:MYratio }\end{array}$ & 0,70 & 0,70 & 0,70 & 0,72 & 7,53 & $\hat{\mathrm{Y}}=0,71$ \\
\hline
\end{tabular}

R. Bras. Zootec., v.33, n.6, p.1897-1908, 2004 (Supl. 1) 
de 0,$02 ; 0,34 ; 0,07 ; 0,65 ; 0,75$ e $\mathrm{R} \$ 0,65$ para bagaço de cana-de-açúcar, farelo de algodão, CF, uréia, sal mineral e MAP, respectivamente, para MN.

$\mathrm{Na}$ Tabela 11, encontram-se as médias dos consumos de MN dos ingredientes das dietas e, na Tabela 12, as médias de produção de leite, a receita com a venda do leite, o custo com alimentação e o retorno financeiro referentes às dietas experimentais.

De acordo com a análise econômica, o custo com alimentação comprometeu 57,87; 60,20; 55,49; e
$50,51 \%$ da receita, para as dietas com $0 ; 10 ; 20$ e $30 \%$ de $\mathrm{CF}$, respectivamente. A dieta contendo $30 \%$ de $\mathrm{CF}$ permite maior retorno financeiro ao produtor, porém, em razão das flutuações sazonais, antes de se fazer a opção, deve-se realizar pesquisa de preços e cálculo atualizado do custo de cada dieta.

Na Tabela 13, são apresentadas as equações de regressão referentes à ingestão de MS e à produção de leite para a primeira, segunda e terceira semanas de todo período experimental.

Tabela 11 - Médias dos consumos dos ingredientes na matéria natural nos quatro tratamentos

Table 11 - Means of intakes of ingredients in natural matter in the four treatments

\begin{tabular}{|c|c|c|c|c|}
\hline \multirow[t]{2}{*}{$\begin{array}{l}\text { Ingredientes }(\mathrm{kg} / \mathrm{dia}) \\
\text { Ingredients }(\mathrm{kg} / \text { day) }\end{array}$} & \multicolumn{4}{|c|}{$\begin{array}{l}\text { Consumo de matéria natural } \\
\text { Intake of natural matter }\end{array}$} \\
\hline & $0 \%$ & $10 \%$ & $20 \%$ & $30 \%$ \\
\hline Palma & 79,81 & 89,51 & 86,50 & 82,25 \\
\hline Forage cactus & & & & \\
\hline $\begin{array}{l}\text { Bagaço de cana-de-açúcar } \\
\text { Sugar cane bagasse }\end{array}$ & 7,21 & 6,61 & 4,58 & 2,72 \\
\hline $\begin{array}{l}\text { F. de algodão } \\
\text { Cottonseed meal }\end{array}$ & 2,83 & 2,92 & 2,23 & 1,70 \\
\hline $\begin{array}{l}\text { Cama de frango } \\
\text { Broiler litter }\end{array}$ & 0,00 & 2,00 & 3,99 & 5,82 \\
\hline $\begin{array}{l}\text { Uréia } \\
\text { Urea }\end{array}$ & 0,21 & 0,20 & 0,14 & 0,06 \\
\hline $\begin{array}{l}\text { Minerais } \\
\text { Minerals }\end{array}$ & 0,08 & 0,10 & 0,09 & 0,02 \\
\hline $\begin{array}{l}\text { MAP } \\
\text { Amonium phosphate - monobasic }\end{array}$ & 0,11 & 0,08 & 0,07 & 0,00 \\
\hline
\end{tabular}

Tabela 12 - Médias da produção de leite, receita com a venda do leite, custo com alimentação e retorno financeiro referentes às dietas experimentais

Table 12 - Means of milk yield, budget of milk, cost of feeding and pay back of diets

\begin{tabular}{|c|c|c|c|c|}
\hline \multirow{2}{*}{$\begin{array}{l}\text { Itens } \\
\text { Items }\end{array}$} & \multicolumn{4}{|c|}{$\begin{array}{l}\text { Níveis de cama de frango } \\
\text { Levels of broiler litter }\end{array}$} \\
\hline & $0 \%$ & $10 \%$ & $20 \%$ & $30 \%$ \\
\hline $\begin{array}{l}\text { Produção de leite, } \mathrm{kg} / \mathrm{dia} \\
\text { Milk yield, } \mathrm{kg} / \text { day }\end{array}$ & 11,71 & 12,57 & 12,22 & 12,18 \\
\hline $\begin{array}{l}\text { Preço do leite, } \mathrm{R} \$ / \mathrm{kg} \\
\text { Milk price }\end{array}$ & 0,32 & 0,32 & 0,32 & 0,32 \\
\hline $\begin{array}{l}\text { Receita, } \mathrm{R} \$ / \text { dia } \\
\text { Budget of milk/day }\end{array}$ & 3,75 & 4,02 & 3,91 & 3,90 \\
\hline $\begin{array}{l}\text { Custo da alimentação, } \mathrm{R} \$ / \text { dia } \\
\text { Cost offeeding, } R \$ / \text { day }\end{array}$ & 2,17 & 2,42 & 2,17 & 1,97 \\
\hline $\begin{array}{l}\text { Retorno, } \mathrm{R} \$ / \text { dia } \\
\text { Pay back/day }\end{array}$ & 1,57 & 1,61 & 1,74 & 1,92 \\
\hline
\end{tabular}

R. Bras. Zootec., v.33, n.6, p.1897-1908, 2004 (Supl. 1) 


\begin{tabular}{|c|c|c|}
\hline Table 13 - & $\begin{array}{l}\text { para os consumos de matéria seca (CMS), em quilograma } \\
\text { a produção de leite }(\mathrm{PL}) \text {, em função dos niveis de cama } \\
\text { das rações utilizadas nas três semanas experimentais } \\
\text { Regression equation and coefficient of determination }\left(R^{2} / \mathrm{r}^{2}\right) \text { for } \\
\text { intakes }(D M I) \text {, express in kilograms/day ( } \mathrm{kg} / \text { day) and percent } \\
\text { weight }(\% L W \text { ) and for milk yeld (MY) express in kilograms } / \text { day } \\
\text { function of levels of broiler litter of rations refers to three experime }\end{array}$ & $\begin{array}{l}\text { /dia para } \\
\text { de frango } \\
\text { dry matter } \\
\text { ge of live } \\
\mathrm{kg} / \text { day), in } \\
\text { ntal weeks }\end{array}$ \\
\hline Semana & Equação & $\mathrm{R}^{2} / \mathrm{r}^{2}$ \\
\hline Week & Equation & $(\%)$ \\
\hline \multicolumn{3}{|c|}{ CMS (kg/dia) } \\
\hline \multicolumn{3}{|c|}{$D M I(\mathrm{~kg} /$ day $)$} \\
\hline 1 & $\hat{\mathrm{Y}}=16,0099-0,033543 * \mathrm{CF}$ & 86,06 \\
\hline 2 & $\hat{\mathrm{Y}}=15,7477+0,113158 * \mathrm{CF}-0,00444761 * \mathrm{CF}^{2}$ & 52,34 \\
\hline 3 & $\hat{\mathrm{Y}}=15,8876+0,181855^{* *} \mathrm{CF}-0,007276^{* *} \mathrm{CF}^{2}$ & 70,17 \\
\hline $2-3$ & $\hat{\mathrm{Y}}=15,8177+0,147506 * * \mathrm{CF}-0,0536209 * * \mathrm{CF}^{2}$ & 52,69 \\
\hline \multirow{2}{*}{\multicolumn{3}{|c|}{$\begin{array}{l}\text { PL }(\mathrm{kg} / \text { dia }) \\
M Y(k g / \text { day })\end{array}$}} \\
\hline & & \\
\hline 1 & $\hat{\mathrm{Y}}=12,36$ & - \\
\hline 2 & $\hat{\mathrm{Y}}=12,11$ & - \\
\hline 3 & $\hat{\mathrm{Y}}=12,18$ & - \\
\hline
\end{tabular}

\section{Conclusões}

A associação palma forrageira, bagaço de canade-açúcar e uréia, com inclusão de até $30 \%$ de cama de frango, pode ser alternativa viável para a produção de leite no agreste pernambucano. Porém, ressalta-se que, atualmente, o uso da cama de frango na alimentação de ruminantes está proibido pelo Ministério da Agricultura, Pecuária e Abastecimento.

O período experimental em ensaios com palma forrageira pode ser reduzido para 14 dias (sete destinados à adaptação e sete para coleta de dados).

\section{Literatura Citada}

ALLEN, M.S. Relationship between fermentation acid production in the rúmen and requeriments for physically effective fiber. Symposium: meeting the fiber requeriments of dairy cows. Journal of Dairy Science, v.80, n.7, p. 1447-1462,1997.

ARIELE, A.; PECTH, Y.; ZAMWELL, S. et al. nutritional adaptation of heifers to diets containing poultry litter. Livestock Production Science, v.28, n.1, p.53-63, 1991.

BEHMER, M.L.A. Laticínios, leite, manteiga, queijo, caseína e instalações. 3.ed. São Paulo: Melhoramentos, 1966. 294p.

CONN, E.E.; STUMPF,P.K. Introdução a bioquímica. 4.ed. São Paulo: Edgar Blucher, 1980. 525p.

R. Bras. Zootec., v.33, n.6, p.1897-1908, 2004 (Supl. 1)
DETMANN, E.; PAULINO, M.F.; ZERVOUDAKIS, J.T. et al. Suplementação de novilhos mestiços durante a época das águas: parâmetros ingestivos e digestivos. Revista Brasileira de Zootecnia, v.30, n.4, p.13401349,2001

FERREIRA, M.A.; MATOS, L.M.; SANTOS, D.C. et al. Associação da palma forrageira (Opuntia ficus indica Mill) com diferentes fontes de fibra na alimentação de vacas mestiças em lactação. In: REUNIÃO DA SOCIEDADE BRASILEIRA DE ZOOTECNIA, 37., 2000, Viçosa, MG. Anais... Viçosa, MG: Sociedade Brasileira de Zootecnia, 2000a. p.332.

FERREIRA, M.A.; WANDERLEY, W.L.; VERAS, A.S. et al. Substituição da silagem de sorgo(Sorgum bicolor, (L.) Moench) pela palma forrageira (Opuntia ficus indica Mill) na alimentação de vacas holandesas em lactação: consumo de nutrientes In: CONGRESSO NORDESTINO DE PRODUÇÃO ANIMAL, 2., SIMPÓSIO NORDESTINO DE ALIMENTAÇÃO DE RUMINANTES, 8., 2000, Teresina. Anais... Teresina: Sociedade Nordestina de Produção Animal, 2000b. p.328-330.

FORBES, J. M. Voluntary food intake and diet selection in farm animals. Wallingford: Cab International, 1995. $532 p$.

LEITE, L. A. Silagem de girassol em substituição à silagem de milho na dieta de vacas leiteiras. Belo Horizonte: Universidade Federal de Minas Gerais, 2002.47p. Dissertação (Mestrado em Produção Animal) - Universidade Federal de Minas Gerais, 2002.

LICITRA, G.; HERNANDEZ, T.M.; Van SOEST, P.J. Standardization of procedures for nitrogen fractionation of ruminant feeds. Animal Feed Science Technology, v.57, p.347-358, 1996. 
MAGALHÃES, M.C.S. Cama de frango associada à palma forrageira (Opuntia ficus-indica Mill) na alimentação de vacas mestiças em lactação. Recife: Universidade Federal Rural de Pernambuco, 2002. 73p. Dissertação (Mestrado em Zootecnia) - Universidade Federal Rural de Pernambuco, 2002.

MELLO, A.A.S.; FERREIRA, M.A.; VÉRAS, A.S.C. et al Substituição parcial do farelo de soja por uréia e palma forrageira (Opuntia ficus indica Mill cv. Gigante) em dietas para vacas em lactação. Revista Brasileira de Zootecnia, v.31, n.3, p.727-736, 2003.

MERTENS, D.R. Creating a system for meeting the fiber requirements of dairy cows. Journal of Dairy Science, v.80, p.1463-1481, 1997.

MERTENS, D.R. Regulation of forage intake. In: FAHEY JR, G.C. (Ed.). Forage quality, evaluation and utilization. Madison: American Society of Agronomy, 1994. p.450-493.

MERTENS, D.R. Análise da fibra e sua utilização na avaliação e formulação de rações. In: SIMPÓSIO INTERNACIONAL DE RUMINANTES, REUNIÃO ANUAL DA SOCIEDADE BRASILEIRA DE ZOOTECNIA, 29., 1992, Lavras. Anais... Lavras: Sociedade Brasileira de Zootecnia, 1992. p.188-219.

MOREIRA, A.L.; PEREIRA, O.G.; GARCIA, R. et al. Produção de leite, consumo e digestibilidade aparente dos nutrientes, $\mathrm{pH}$ e concentração de amônia ruminal em vacas lactantes recebendo rações contendo silagem de milho e feno de alfafa e de capim- Coastcross. Revista Brasileira de Zootecnia, v.30, n.3, p.1089-1098, 2001 (Suplemento 1).

NATIONAL RESEARCH COUNCIL - NRC. Nutrient requirements of the dairy cattle. 6.ed. Washington, D.C: National Academy Press, 1989. 158p.

NATIONAL RESEARCH COUNCIL - NRC. Nutrient requirements of the dairy cattle. 6.ed. Washington, D.C: National Academy Press, 2001. 381p.

OLIVEIRA, A.S.; VALADARES, R.F.D.; RENNÓ, L.N. et al. Consumo, digestibilidade aparente, produção e composição do leite em vacas alimentadas com quatro níveis de compostos nitrogenados não-protéicos. Revista Brasileira de Zootecnia, v.30, n.4, p.1358-1366, 2001.

PEREIRA, E.S.; ARRUDA, A.M.V.; MIRANDA, L.F. et al. Consumo e digestibilidade aparente em vacas Holandesas lactantes alimentadas com diferentes silagens. In: REUNIÃO DA SOCIEDADE BRASILEIRA DE ZOOTECNIA, 39., 2002, Recife. Anais... Recife: Sociedade Brasileira de Zootecnia, 2002, CD-ROM. Nutrição de Ruminantes.

PEREIRA, E.S.; QUEIROZ, A.C.; PAULINO, M.F. et al. Determinação das frações protéicas e de carboidratos e taxas de degradação in vitro da cana de açúcar, da cama de frango e do farelo de algodão. Revista Brasileira de Zootecnia, v.29, n.6, p.1887-1893, 2000
PEREIRA, E.S.; QUEIROZ, A.C.; PAULINO, M.F. et al. Fontes nitrogenadas e uso de Sacharomyces cerevisiae em dietas à base de cana-de-açúcar para novilhos: consumo, digestibilidade, balanço nitrogenado e parâmetros ruminais. Revista Brasileira de Zootecnia, v.30, n.2, p.563-572, 2001 .

REGAZZI, J.A. Teste para verificar a identidade de modelos de regressão. Pesquisa Agropecuária Brasileira, v.31, n.1, p.1-17, 1996.

SAMPAIO, I.B.M. Estatística aplicada à experimentação animal. Belo Horizonte: Fundação de Ensino e Pesquisa em Medicina Veterinária, 1998. 221p.

SANTANA, P.; VIANA, S.P.; ESTIMA, A.L. et al. Palma versus silagem na alimentação de vacas leiteiras. Revista Brasileira de Zootecnia, v.1, n.1, p.31-40, 1972.

SANTOS, D.C.; FARIAS, I.; LIRA, M.A.; TAVARES FILHO, J.J. et al. A palma forrageira (Opuntia ficus-indica Mill e Nopalea cochenillifera Salm-Dick) em Pernambuco: cultivo e utilização. Recife: Empresa Pernambucana de Pesquisa Agropecuária, 1997. 23p. (Documentos, 25).

SILVA, D.J. Análise de alimentos (métodos químicos e biológicos). Viçosa, MG: Universidade Federal de Viçosa, 1990. 165 p.

SNIFFEN, C.J.; O'CONNOR, J.D.; Van SOEST, P.J. A net carbohydrate and protein system for evaluating cattle diets. II. Carbohydrate and protein availability. Journal of Animal Science, v.70, p.3562-3577, 1992.

UNIVERSIDADE FEDERAL DE VIÇOSA - UFV. SAEG Sistemas de Análises Estatísticas e Genéticas. Versão 7.1. Viçosa, MG: 1997. 150p. (Manual do usuário).

VALADARES FILHO, S.C.; BRODERICK, G.A.; VALADARES, R.F.D. et al. Effect of replacing alfalfa silage with high moisture corn on nutrient utilization and milk production. Journal of Animal Science, v.83, p.106-114, 2000.

Van SOEST, P.J.; ROBERTSON, J.B.; LEWIS, B.A. Methods for dietary fiber, neutral detergent fiber, and nonstarch polysaccharides in relation to animal nutrition. Journal of Animal Science, v.74, p.3583-3597, 1991. 